\title{
Prevalence of information gaps for seniors transferred from nursing homes to the emergency department
}

\author{
Matthew A. Cwinn, MSc; ${ }^{*}$ Alan J. Forster, MD, MSc; ${ }^{\dagger}$ A. Adam Cwinn, MD; ${ }^{*}$ Guy Hebert, MD; ${ }^{*}$ \\ Lisa Calder, MD, MSc; ${ }^{*}$ Ian G. Stiell, MD, MSc*
}

\section{ABSTRACT}

Objective: Information gaps, defined as previously collected information that is not available to the treating physician, have implications for patient safety and system efficiency. For patients transferred to an emergency department (ED) from a nursing home or seniors residence, we determined the frequency and type of clinically important information gaps and the impact of a regional transfer form.

Methods: During a 6-month period, we studied consecutive patients who were identified through the National Ambulatory Care Reporting System database. Patients were over 60 years of age, lived in a nursing home or seniors residence, and arrived by ambulance to a tertiary care ED. We abstracted data from original transfer and ED records using a structured data collection tool. We measured the frequency of prespecified information gaps, which we defined as the failure to communicate information usually required by an emergency physician (EP). We also determined the use of the standardized patient transfer form that is used in Ontario and its impact on the rate of information gaps that occur in our community.

Results: We studied 457 transfers for 384 patients. Baseline dementia was present in $34.1 \%$ of patients. Important information gaps occurred in $85.5 \%$ (95\% confidence interval $[\mathrm{Cl}]$ $82.0 \%-88.0 \%)$ of cases. Specific information gaps along with their relative frequency included the following: the reason for transfer $(12.9 \%)$, the baseline cognitive function and communication ability $(36.5 \%)$, vital signs $(37.6 \%)$, advanced directives $(46.4 \%)$, medication $(20.4 \%)$, activities of daily living $(53.0 \%)$ and mobility $(47.7 \%)$. A standardized transfer form was used in $42.7 \%$ of transfers. When the form was used, information gaps were present in $74.9 \%$ of transfers compared with $93.5 \%$ of the transfers when the form was not used ( $p<0.001)$. Descriptors of the patient's chief complaint were frequently absent $(81.0 \%$ for head injury [any information about loss of consciousness], $42.4 \%$ for abdominal pain and $47.1 \%$ for chest pain [any information on location, severity and duration]).

Conclusion: Information gaps occur commonly when elderly patients are transferred from a nursing home or seniors residence to the ED. A standardized transfer form was associated with a limited reduction in the prevalence of information gaps; even when the form was used, a large percentage of the transfers were missing information. We also determined that the lack of descriptive detail regarding the presenting problem was common. We believe this represents a previously unidentified information gap in the literature about nursing home transfers. Future research should focus on the clinical impact of information gaps. System improvements should focus on educational and regulatory interventions, as well as adjustments to the transfer form.

Keywords: emergency department, information gaps, patient transfers, nursing homes, patient safety, geriatrics

\section{RÉSUMÉ}

Objectif : Les lacunes dans l'information, définies comme des renseignements recueillis précédemment dont le médecin traitant ne dispose pas, ont une incidence sur la sécurité des patients et l'efficacité du système. Nous avons déterminé, pour les patients transférés à un service d'urgence à partir d'un foyer de soins ou d'une résidence de personnes âgées, la fréquence et le type de lacunes en matière d'information cliniques importantes ainsi que l'impact d'un formulaire de transfert régional.

Méthodes : Au cours d'une période de 6 mois, nous avons étudié des patients admis consécutivement qui avaient été repérés à I'aide de la base de données du Système national d'information sur les soins ambulatoires. Ils avaient plus de 60 ans, vivaient dans une maison de soins infirmiers ou une résidence de personnes âgées et étaient arrivés en ambulance à l'urgence d'un hôpital de soins tertiaires. Nous avons extrait des données du transfert initial et des dossiers de l'urgence à l'aide d'un outil structuré de collecte de données. Nous avons mesuré la fréquence de lacunes dans l'information précisées au préalable, que nous avons définies comme l'incapacité de communiquer des renseignements habituelle-

From the *Department of Emergency Medicine, University of Ottawa, Ottawa, Ont. and the tDepartment of Medicine, University of Ottawa, Clinical Epidemiology Program, Ottawa Health Research Institute, Ottawa, Ont.

Submitted May 20, 2008; Revised Nov. 23, 2009; Accepted Jan. 26, 2009

This article has been peer reviewed. 
ment exigés par un médecin d'urgence. Nous avons également déterminé l'utilisation du formulaire normalisé de transfert de patients qui est utilisé en Ontario et son impact sur le taux de lacunes dans l'information qui se produisent dans notre collectivité.

Résultats : Nous avons étudié 457 transferts pour 384 patients. La démence était présente au départ chez $34,1 \%$ des patients. D'importantes lacunes en matière d'information sont survenues dans $85,5 \%$ des cas (intervalle de confiance [IC] à $95 \%$ de 82,0 à 88,0\%). Des lacunes en matière d'information particulière ainsi que leur fréquence relative portaient sur les sujets suivants : le motif du transfert (12,9\%); les fonctions cognitives au départ et la capacité de communication $(36,5 \%)$; les signes vitaux $(37,6 \%)$; des directives préalables $(46,4 \%)$; la prise de médicaments $(20,4 \%)$; les activités de la vie quotidienne (53,0\%); et la mobilité $(47,7 \%)$. Un formulaire de transfert normalisé a été utilisé dans $42,7 \%$ des transferts. On a noté des lacunes dans $74,9 \%$ des transferts quand le formulaire était utilisé, et dans $93,5 \%$ des transferts lorsqu'il ne l'était pas $(p<0,001)$. Les descripteurs du principal motif de consultation du patient étaient souvent absents, par exem- ple, $81 \%$ pour les blessures à la tête (aucune information sur la perte de conscience); $42,4 \%$ pour des douleurs abdominales et $47,1 \%$ pour les douleurs thoraciques (aucune information sur le point de douleur, la gravité ou la durée).

Conclusion : Les lacunes en matière d'information se produisent fréquemment lorsque les patients âgés sont transférés à l'urgence à partir d'un foyer de soins ou d'une résidence de personnes âgées. L'utilisation d'un formulaire de transfert normalisé n'a permis de réduire que très peu la prévalence des lacunes en matière d'information. En effet, même lorsqu'il était utilisé, nous avons constaté un manque d'information pour un pourcentage important des transferts. Nous avons également déterminé que l'absence de description détaillée en ce qui concerne le motif de consultation était fréquente. Nous sommes d'avis que cela représente une lacune dans l'information non repérée précédemment dans la littérature sur les transferts de maisons de soins infirmiers. Les études futures devraient se concentrer sur l'impact clinique des lacunes dans I'information. L'amélioration du système devrait être axée sur des interventions éducatives et réglementaires, ainsi que sur la modification du formulaire de transfert.

\section{INTRODUCTION}

Information gaps are defined as previously collected clinical information that is required for patient care but is not available to the treating physician. ${ }^{1,2}$ Information gaps are important to emergency physicians (EPs) because they seldom have immediate access to all of the background clinical information of their patients. ${ }^{3}$ Moreover, many patients may be unable to provide accurate or complete health information on their arrival in the emergency department (ED). Information gaps may impede the provision of effective, efficient and safe health care in the ED and elsewhere..$^{1,4}$

Information gaps may be particularly important for ED patients who are transferred from nursing homes. This is especially so for those patients who are cognitively impaired and may not be able to describe their past and present health information. ${ }^{5}$ With the aging population, EPs are caring for increasing numbers of nursing home patients with complex multisystem problems, including dementia.

In ideal circumstances, nursing home patients transferred to an ED are accompanied with clear and concise documentation describing important clinical information. For example, such documentation should include sufficient details about the new symptoms or the problems that prompted the transfer to the ED, the patient's baseline cognitive function and his or her ability to communicate, descriptions of any changes from base- line, the relevant medical history, the medication history and any advanced directives. This information is routinely available to the nursing home staff and could be easily communicated at the time of transfer. The failure to do so could lead to undesirable outcomes due to clinical uncertainty, for example, the performance of unnecessary tests or interventions could in turn lead to errors or an increase in the ED length of stay.

As part of a regional approach to improving transfer documentation, we sought to measure the prevalence of information gaps that occurred when patients were transferred to our facility from a nursing home or seniors residence. This measurement is informative because it describes the current state of affairs. We also assessed the effectiveness of a regionally standardized transfer form on reducing information gaps in our region.

\section{METHODS}

We conducted our study at a teaching hospital with emergency medicine training programs. There were 58014 patient visits during the period studied (January through June 2004) and 12367 (21.3\%) of the patients arrived by ambulance. We performed a structured health records review in which we used a standardized data collection tool developed for this study to abstract data from original transfer documents and the ED record of treatment including staff nurse notes. Our research ethics board approved the study. 
The study population included consecutive patients 60 years or older who were transferred by ambulance from a nursing home or seniors residence within a 6-month period in 2004. Nursing homes generally provide a higher level of support staff and services to the elderly than do seniors residences. Nevertheless, we included both types of originating facilities; in practice it is often unclear to the ED staff which type of originating facility the patient is from and what support services are available there. For brevity we have used the term "nursing home" here to encompass both types of facilities. The transfer was the unit of analysis, so we studied each one for patients transferred more than once during the study period. We excluded patients who were transferred so they could be seen by a specialty service other than emergency medicine because of the possibility that previous telephone or written communication could have taken place. Ambulance records for the transfer, when available, were not reviewed as part of this study; we wished to examine what information the nursing home staff, who generally have a long acquaintance with these patients, felt was important to convey directly to the EP. The first consecutive 6 months of 2004 were chosen as a convenience sample that also included transfers for problems that might have seasonal variation between winter and summer. This sample period was the most recent period for which appropriate data was available.

\section{Data collection and chart abstraction}

Our hospital participates fully in the National Ambulatory Care Reporting System (NACRS) database. Health records personnel are required to examine the ED charts of every ED patient and abstract and code information in a standardized manner, which is then submitted and included in the NACRS database. We used the NACRS database as it was the most accurate means of ensuring capture of all transfers from all the nursing homes and seniors residences in our region. We accessed these data for the Ottawa Hospital, Civic Campus, in order to identify all patients aged 60 years or older who were transferred from a nursing home or seniors residence by ambulance to this ED during the period studied. In addition, we used the following data elements from NACRS: hospital number, registration date, age, sex, Canadian Emergency Department Triage and Acuity Score (CTAS), ${ }^{6}$ the name of the originating nursing home or seniors residence, discharge disposition, imaging and procedures performed and final diagnosis. Using a structured data abstraction form that was designed specifically for this study, we then reviewed the hospital health records in detail, including the EP and nursing notes and all transfer documents, for each transfer. We abstracted data from the documentation that was sent with the patients from the nursing homes. Data collection was performed by an experienced EP and an undergraduate university student. The requirements to satisfy each category on the data abstraction form were defined before data collection and the student was trained by the EP on the use of this form as well as the procedures to find the data in the hospital health record. A series of charts were analyzed by the student under close supervision. The supervising physician subsequently checked data collection forms randomly to ensure accuracy and completeness; any difficult cases were set aside for the physician to review. As the data elements were objective and did not require interpretation, interobserver agreement was not performed; the data was either present or absent in the transfer documentation.

We measured information gaps for important clinical parameters, gaps in descriptive details of the presenting problem, and the effectiveness of a standardized form in reducing gaps. To evaluate whether or not clinically important information gaps were present in the patient transfer documentation, we determined, based on criteria described in previously published studies, ${ }^{7-9}$ that 11 essential clinical data elements should be present on documentation accompanying every patient transferred: 1) reason for transfer to the $E D, 2$ ) baseline cognitive function and communication ability, 3) vital signs at time of complaint, 4) advanced directives for level of care and resuscitation, 5) medication, 6) activities of daily living, 7) immunization status if wounded, 8) allergy status, 9) mobility, 10) bowel continence and 11) bladder continence. Any patient transfer documentation that was missing at least 1 of these elements was deemed to have a clinically important information gap. The authors' consensus opinion is that elements 1-5 were essential for the EP and these items received particular attention in the analysis.

A standardized transfer form for interfacility transfers is currently in use by many nursing homes and seniors residences in our region (Appendix 1). This form has been available for many years from the Ontario Hospital Association and has been used routinely for transfers from nursing homes in this province to the ED. It was last revised in 1999 based on input that the Ontario Hospital Association received from nursing homes, 
seniors residences, long-tem care centres and hospitals in Ontario. It is available for purchase from the Ontario Hospital Association ${ }^{10}$ as a 3-copy, carbonless form (i.e., original to accompany patient, first copy for receiving facility, second copy for sending facility).

This 1-page transfer form has areas for nursing home staff to enter clinical information, including the essential 11 clinical elements studied, and is structured with tick boxes and areas for narrative description, as well as areas for recording administrative patient information. We examined the adequacy of transfer documentation when either this standardized form or, alternatively, an institution-specific form or hand-written narrative was used. Patients that had no transfer documentation on file in their hospital medical records were tallied, but excluded from analysis.

\begin{tabular}{|c|c|}
\hline Characteristic & No. $(\%)$ of transfers* $†$ \\
\hline Female & $322(70.5)$ \\
\hline Mean age, yr & 83.9 \\
\hline Dementia & $156(34.1)$ \\
\hline \multicolumn{2}{|l|}{ Referring institution, $n=32$} \\
\hline Nursing home & 388 (84.9) \\
\hline Seniors residence & $69(15.1)$ \\
\hline \multicolumn{2}{|l|}{ Presenting complaint $\ddagger$} \\
\hline Trauma & $96(21.0)$ \\
\hline General complaints & $90(19.7)$ \\
\hline $\mathrm{Gl}$ & $80(17.5)$ \\
\hline Respiratory & $80(17.5)$ \\
\hline Neurological & $67(14.7)$ \\
\hline Cardiac & 36 (7.9) \\
\hline Infectious disease & $29 \quad(6.3)$ \\
\hline Other & 109 (23.9) \\
\hline \multicolumn{2}{|l|}{ Triage category§ } \\
\hline Resuscitation & $12(2.6)$ \\
\hline Emergent & $65(14.2)$ \\
\hline Urgent & 309 (67.6) \\
\hline Less urgent & 61 (13.3) \\
\hline Nonurgent & $10 \quad(2.2)$ \\
\hline \multicolumn{2}{|l|}{ Disposition } \\
\hline Admitted to hospital & $136(29.8)$ \\
\hline Discharged & 228 (49.9) \\
\hline Transferred & $84(18.4)$ \\
\hline ICU/OR & $4 \quad(0.9)$ \\
\hline Died & $4 \quad(0.9)$ \\
\hline Unknown & $1 \quad(0.2)$ \\
\hline Standardized patient transfer form used & $195(42.7)$ \\
\hline \multicolumn{2}{|c|}{$\begin{array}{l}\mathrm{GI}=\text { gastrointestinal; } \mathrm{ICU}=\text { intensive care unit; } \mathrm{OR}=\text { operating room. } \\
\text { *Unless otherwise indicated. } \\
+380 \text { patients seen with } 457 \text { transfers. Transfer is the unit of analysis. } \\
\text { +Some patients were transferred with more than one complaint. } \\
\text { \$Canadian Emergency Department Triage and Acuity Scale. }\end{array}$} \\
\hline
\end{tabular}

To evaluate gaps in the richness of descriptive detail of transfer information, we determined key descriptors that would be useful to have for each category of complaint based on consensus opinion of the authors. We documented whether there was any description of baseline cognitive function and communication ability, including the following: orientation, dementia, forgetfulness, ability to communicate and alertness. We also measured whether it was clear from the transfer notes if abnormal cognitive function and communication ability was a new problem or was a baseline deficit. If any of these descriptors were absent in the transfer documentation, the patient was deemed to have a qualitative information gap.

Our statistical analyses included univariate statistical tests as appropriate for the data. We used SAS statistical software.

\section{RESULTS}

There were 457 consecutive transfers of 380 patients from 32 referring institutions during the study period for which all appropriate records could be obtained for review. Of these patients, $319(83.9 \%)$ had 1 transfer, 51 $(13.4 \%)$ had 2 transfers, $8(2.1 \%)$ had 3 transfers, 1 $(0.3 \%)$ had 4 transfers and $1(0.3 \%)$ had 8 transfers.

\begin{tabular}{|c|c|}
\hline Clinically important information & $\begin{array}{c}\text { No. (\%) of } \\
\text { transfers with } \\
\text { information gaps }\end{array}$ \\
\hline $\begin{array}{l}\text { Composite of } 11 \text { most important clinical } \\
\text { criteria }\end{array}$ & $391(85.6) \dagger$ \\
\hline Reason for transfer* & 59 (12.9) \\
\hline $\begin{array}{l}\text { Baseline cognitive function and } \\
\text { communication ability* }\end{array}$ & $167(36.5)$ \\
\hline Vital signs at time of complaint* & $172(37.6)$ \\
\hline Advanced directives indicated* & $212(46.4)$ \\
\hline Medication (name, dose and legible)* & $93(20.4)$ \\
\hline Activity of daily living & $242(53.0)$ \\
\hline $\begin{array}{l}\text { Tetanus immunization if wound is reason } \\
\text { for transfer }\end{array}$ & $33 \quad(7.2)$ \\
\hline Allergy status & 29 (6.3) \\
\hline Mobility & $218(47.7)$ \\
\hline Bladder continence & $215(47.0)$ \\
\hline Bowel continence & $221(48.4)$ \\
\hline $\begin{array}{l}\text { Composite of } 5 \text { most essential clinical } \\
\text { criteria }\left({ }^{*}\right) \text { for the emergency physician }\end{array}$ & $361(79.0) \neq$ \\
\hline
\end{tabular}


There were an additional 133 transfers during the study period for which documentation from the nursing homes was unavailable in the hospital medical record at the time of review. These transfers were therefore excluded from further analysis. Table 1 describes the characteristics of the patient visits.

Of the 457 transfers, at least 1 information gap existed in $85.6 \%$ of the cases $(95 \%$ CI $82.0 \%-88.0 \%$ ) (Table 2 ). With respect to the 5 information categories that were considered to be of essential importance to treating EPs at least 1 information gap occurred in $79.0 \%$ of all transfers (95\% CI 76.5\%-81.5\%). Specific information gaps and their frequencies are documented in Table 2.

The standardized transfer form was used in $42.7 \%$ of the transfers to the ED. Overall, at least 1 information gap occurred in $74.9 \%$ of transfers when a standardized transfer form was used compared with $93.5 \%$ of transfers when no such form was used $(p<0.001)$ (Table 3 ).

Although the majority of the transfers examined involved transfer to the ED from a nursing home, we addressed the possibility of heterogeneity between patients who were sent to the ED from a nursing home or from a seniors residence by performing subgroup analysis on these 2 populations. There was no statistical difference between either group in the proportion of

Table 3. Effects of a standardized patient transfer form on the prevalence of information gaps

\begin{tabular}{|c|c|c|c|}
\hline \multirow[b]{2}{*}{ Clinically important criteria } & \multicolumn{3}{|c|}{$\begin{array}{l}\text { No. (\%) of transfers with } \\
\text { information gaps }\end{array}$} \\
\hline & $\begin{array}{l}\text { Standardized } \\
\text { form used, } \\
n=195\end{array}$ & $\begin{array}{l}\text { Instit } \\
\text { specific } \\
\text { used, } r\end{array}$ & $\begin{array}{l}\text { ution- } \\
\text { c record } \\
n=262\end{array}$ \\
\hline $\begin{array}{l}\text { Composite of eleven } \\
\text { clinically important criteria* }\end{array}$ & $146(74.9)$ & 245 & (93.5) \\
\hline Reason for transfer stated* & 9 (4.6) & 50 & $(19.1)$ \\
\hline $\begin{array}{l}\text { Baseline cognitive function } \\
\text { and communication ability* }\end{array}$ & $43(22.1)$ & 124 & $(47.3)$ \\
\hline $\begin{array}{l}\text { Vital signs at time of } \\
\text { complaint }\end{array}$ & $71(36.4)$ & 101 & $(38.5)$ \\
\hline $\begin{array}{l}\text { Advanced directives } \\
\text { indicated }\end{array}$ & $88(45.1)$ & 124 & $(47.3)$ \\
\hline Medicationt & 27 (13.8) & 66 & $(25.2)$ \\
\hline Activities of daily living* & $45(23.1)$ & 197 & $(75.2)$ \\
\hline $\begin{array}{l}\text { Tetanus immunization if } \\
\text { wound is reason for transfer }\end{array}$ & $13 \quad(6.7)$ & 20 & (7.6) \\
\hline Allergy status & 9 (4.6) & 20 & $(7.7)$ \\
\hline Mobility* & $39(20.0)$ & 179 & (68.3) \\
\hline Bladder continence* & $43(22.1)$ & 172 & $(65.6)$ \\
\hline Bowel continence* & $44(22.6)$ & 177 & $(67.6)$ \\
\hline
\end{tabular}

transfers presenting with trauma, general complaints, or gastrointestinal, respiratory, neurologic, cardiac, infectious disease or other complaints (data not shown). The percentage of transfers that used the standardized collection form did not significantly differ between groups: the standardized transfer form was used in $165(42.5 \%)$ of the transfers from a nursing home and $30(43.5 \%)$ of the transfers from seniors residence $(p=0.88)$. Both groups had information gaps in each of the categories examined (Table 4). The frequency of information gaps observed in the transfers from a nursing home alone was similar to the frequency observed for both nursing homes (Table 2) and seniors residences combined (Table 4). Although transfer documentation from seniors residences generally had significantly more information gaps than transfer documentation from nursing homes, the trend observed indicates that information gaps are prevalent in both populations. Because of the overall similarities between the 2 groups, we conducted further analysis on transfers from all institutions combined; we refer to all the sending institutions as nursing homes for simplicity.

Table 4. Subgroup analysis of the prevalence of information gaps from the most important clinical data elements in 388 transfers from nursing homes compared with 69 transfers from seniors residences

\begin{tabular}{|c|c|c|}
\hline \multirow[b]{2}{*}{ Clinically important information } & \multicolumn{2}{|c|}{$\begin{array}{l}\text { No. (\%) of transfers with } \\
\text { information gaps }\end{array}$} \\
\hline & Nursing home & $\begin{array}{l}\text { Seniors } \\
\text { residences }\end{array}$ \\
\hline $\begin{array}{l}\text { Composite of eleven clinically } \\
\text { important criteria* }\end{array}$ & $325(83.8)$ & 66 (95.7) \\
\hline Reason for transfert & $47(12.1)$ & 12 (17.4) \\
\hline $\begin{array}{l}\text { Baseline cognitive function } \\
\text { and communication ability†‡ }\end{array}$ & $132(34.0)$ & $35(50.7)$ \\
\hline $\begin{array}{l}\text { Vital signs at time of } \\
\text { complaint* }{ }^{*}\end{array}$ & $132(34.0)$ & $40(58.0)$ \\
\hline $\begin{array}{l}\text { Advanced directives } \\
\text { indicated†‡ }\end{array}$ & $167(43.0)$ & $45(65.2)$ \\
\hline $\begin{array}{l}\text { Medication (name, dose, } \\
\text { legible)* }{ }^{*}\end{array}$ & $74(19.1)$ & 19 (27.5) \\
\hline Activities of daily living* & $197(50.8)$ & $45(65.2)$ \\
\hline $\begin{array}{l}\text { Tetanus immunization if } \\
\text { wound is reason for transfer }\end{array}$ & $28(7.2)$ & $5(7.2)$ \\
\hline Allergy status* & $20(5.2)$ & $9(13.0)$ \\
\hline Mobility $\ddagger$ & $175(45.1)$ & $43(62.3)$ \\
\hline Bladder continence* & $172(44.3)$ & $43(62.3)$ \\
\hline Bowel continence* & 178 (45.9) & $43(62.3)$ \\
\hline $\begin{array}{l}\text { Composite of } 5 \text { most } \\
\text { essential clinical criteria ( } \dagger \text { ) for } \\
\text { the emergency physician* }\end{array}$ & $296(76.3)$ & $65(94.2)$ \\
\hline $\begin{array}{l}{ }^{*} p<0.05 \text {. } \\
+ \text { Composite of } 5 \text { most essential clinical } c r \\
\neq p<0.005 .\end{array}$ & for the emerge & sician. \\
\hline
\end{tabular}


Descriptive clinical detail regarding the patient's presenting complaint was often lacking in the transfer documentation (Table 5). Examples of missing information include any with regard to the loss of consciousness for those transferred for head injury, the onset or duration of the problem for those transferred because they were not eating, and tetanus immunization status if the reason for transfer was a wound. The frequency of missing information regarding medication history was notable. Of all transfers, 427 (93.4\%) had medication history sent. Of these, the medication name was cut off during photocopying for $63(14.8 \%)$ and $8(1.9 \%)$ of the handwritten medication names were illegible.

Of the 457 transfers studied, there was no description of baseline cognition in $36.5 \%$ and no description of baseline orientation in $46.6 \%$. In $156(34.1 \%)$ of the 457 transfers, the patients were reported to have baseline dementia and of these, medical concern leading to transfer was not specified in $12(7.7 \%)$.

In 236 transfers, the Glasgow Coma Scale (GCS)

\begin{tabular}{|c|c|c|c|}
\hline History & $\begin{array}{l}\text { No. of } \\
\text { transfers }\end{array}$ & $\begin{array}{l}\text { Descriptor/modifier } \\
\text { studied }\end{array}$ & $\begin{array}{l}\text { No. (\%) with } \\
\text { no descriptor } \\
\text { provided }\end{array}$ \\
\hline Trauma & 96 & $\begin{array}{l}\text { Area of possible } \\
\text { injury described }\end{array}$ & $15(15.6)$ \\
\hline Head injury & 21 & $\begin{array}{l}\text { Any information } \\
\text { regarding loss of } \\
\text { consciousness }\end{array}$ & $17(81.0)$ \\
\hline Wound & 37 & $\begin{array}{l}\text { Tetanus } \\
\text { immunization status }\end{array}$ & 33 (89.2) \\
\hline Chest pain & 34 & $\begin{array}{l}\text { Information } \\
\text { regarding any of: } \\
\text { duration, location, } \\
\text { quality, radiation }\end{array}$ & $16(47.1)$ \\
\hline $\begin{array}{l}\text { Abdominal } \\
\text { pain }\end{array}$ & 33 & $\begin{array}{l}\text { Information } \\
\text { regarding any of: } \\
\text { duration, location, } \\
\text { severity, radiation }\end{array}$ & $14(42.4)$ \\
\hline Syncope & 16 & Duration & $12(75.0)$ \\
\hline $\begin{array}{l}\text { Confusion or } \\
\text { decreased } \\
\text { level of } \\
\text { consciousness }\end{array}$ & 23 & $\begin{array}{l}\text { Any description or } \\
\text { details }\end{array}$ & $16(69.6)$ \\
\hline Vomiting & 27 & Number of episodes & 7 (25.9) \\
\hline Diarrhea & 17 & Number of episodes & $4(23.5)$ \\
\hline Not eating & 27 & Onset or duration & $18(66.7)$ \\
\hline Dehydration & 20 & $\begin{array}{l}\text { Any of: oral intake } \\
\text { urine output, } \\
\text { vomiting, diarrhea }\end{array}$ & $15(75.0)$ \\
\hline $\begin{array}{l}\text { General } \\
\text { weakness }\end{array}$ & 41 & $\begin{array}{l}\text { Any further } \\
\text { description }\end{array}$ & $35(85.4)$ \\
\hline Fever & 18 & Value & 0 \\
\hline
\end{tabular}

score, as measured by the ED nurse, was evaluated against documentation of the baseline function by the nursing home staff and incomplete transfer information was found (Table 6). Nursing homes were more likely to provide information regarding baseline function for transfers for which the GCS was abnormal at 12-14 compared with normal $(p<0.001)$.

The ED nurse recorded the GCS best verbal response for $252(55.1 \%)$ of the transfers. In all 5 categories, ranging from none to oriented, there were gaps in transfer documentation of baseline cognitive function (Table 6).

Of 82 transfers for which computed tomography (CT) of the head was performed, 31 (37.8\%) did not have transfer information on baseline cognitive and communication status.

To evaluate whether there was variability among nursing homes in the completion of transfer documentation, we examined the documentation sent by the nursing homes that initiated the highest number of transfers (i.e., 23-41 transfers, $n=6$ ) for information gaps. There was considerable variability among the nursing homes, as some homes had a low prevalence of gaps in some categories, and others had a high prevalence (Table 7).

\section{DISCUSSION}

To our knowledge, this is the first report on clinically important information gaps found in transfer documentation when patients are sent to the ED from nursing homes or seniors residences in a Canadian health care

\begin{tabular}{|c|c|c|}
\hline ED nursing assessment & $\begin{array}{l}\text { No. of } \\
\text { transfers }\end{array}$ & $\begin{array}{c}\text { Baseline cognitive } \\
\text { function not described } \\
\text { on transfer notes, } \\
\text { no. (\%) }\end{array}$ \\
\hline \multicolumn{3}{|c|}{ Glasgow Coma Scale score } \\
\hline $15^{*}$ & 116 & $53(45.7)$ \\
\hline $12-14^{*}$ & 99 & $21(21.2)$ \\
\hline 9-11 & 21 & $5(23.8)$ \\
\hline \multicolumn{3}{|l|}{ Verbal response } \\
\hline Oriented & 116 & $54(46.6)$ \\
\hline Confused & 91 & $19(20.9)$ \\
\hline Inappropriate & 12 & 1 (8.3) \\
\hline Incomprehensible & 13 & $5(38.5)$ \\
\hline None & 20 & $4(20.0)$ \\
\hline
\end{tabular}


system. At least 1 information gap was present in $85.5 \%$ of cases, and even a standardized form did not eliminate these gaps. We found that, overall, information gaps occurred in the 5 areas deemed to be critical to the treating physician in $79.0 \%$ of the transfers. These gaps indicate that the high prevalence of information gaps observed overall is not biased by a high number of gaps in the less critical data elements. Furthermore, information sent was often incomplete. For medications, the information was incomplete in $14.8 \%$ of transfer documents. For the chief complaint, important descriptor information was missing in $202(49.3 \%)$ of 410 transfers for which richness of descriptive detail could be analyzed. Of particular concern was the lack of description of the patient's baseline mental status and cognitive function in many of the transfers, particularly in cases for which the GCS was abnormal or the patient required a CT scan of the head. A simple statement describing the patient's baseline mentation, cognitive state, ability to communicate and in what way this has changed from baseline would be very useful to the EP. The high prevalence of information gaps in our large sample of nursing homes indicates that this is a systemic problem rather than an issue with particular nursing homes. Patients residing in seniors residences are less dependent on support services and more likely to be mobile and be able to give a medical history than those in nursing homes. We observed more information gaps in transfer documentation from the seniors residences, but these may have less clinical relevance than information gaps in nursing home patient transfers with the exception of medication and allergy status. Importantly, because $84.9 \%$ of the population studied was trans-

Table 7. Variability in information gaps among the individual nursing homes that initiated the highest number of transfers. The number of transfers from these 6 nursing homes ranged from 23 to 41

\begin{tabular}{|c|c|c|}
\hline \multirow[b]{2}{*}{ Clinically important criteria } & \multicolumn{2}{|c|}{$\begin{array}{c}\% \text { of transfers with information } \\
\text { gaps }\end{array}$} \\
\hline & $\begin{array}{l}\text { Nursing home } \\
\text { with most } \\
\text { complete } \\
\text { documentation }\end{array}$ & $\begin{array}{l}\text { Nursing home } \\
\text { with least } \\
\text { complete } \\
\text { documentation }\end{array}$ \\
\hline Reason for transfer stated* & 0.0 & 13.8 \\
\hline Vital signs & 8.7 & 30.8 \\
\hline $\begin{array}{l}\text { Baseline cognition or } \\
\text { mentationt }\end{array}$ & 37.5 & 62.5 \\
\hline Activities of daily living $†$ & 6.2 & 97.6 \\
\hline $\begin{array}{l}{ }^{*} p \leq 0.05 . \\
+p \leq 0.001 .\end{array}$ & & \\
\hline
\end{tabular}

ferred from nursing homes, the effect of information gaps seen in the transfers from seniors residences had no meaningful effect on information gaps that were observed overall. Table 2 and Table 4 show that the nursing home information gaps were almost the same.

We did not study information gaps in the documentation sent by the ED to the nursing home when patients were returned.

Our data are consistent with previous efforts to measure adequacy of transfer information from nursing homes to the ED. Previously, Jones and coauthors ${ }^{7}$ described a high prevalence of information gaps in a system with no standardized transfer form. Madden and colleagues ${ }^{8}$ implemented a standardized transfer form and although information gaps persisted despite the form, ED staff reported that it made caring for the patients easier. Terrel and coworkers ${ }^{9}$ found that essential information was transmitted on $58.5 \%$ of 65 transfers before the introduction of their standardized form and $77.8 \%$ of 72 transfers after the introduction. Although their standardized form was only used by nursing home staff in 23 (one-third) of postintervention transfers, they found a high degree of completeness of documentation, which they also attribute to the brevity of the form. In contrast, ours is the first study to evaluate both the extent of information gaps and the specific content of information gaps for nursing home transfer documentation as well as to measure the effect of an established standardized patient transfer form. The methodology of our study, as well as the large sample size we examined, allowed us to accurately determine the extent of the problem; the trends in poor transfer documentation previously reported ${ }^{7-9}$ are quantified in this Canadian system.

Previous studies analyzed the effect of the transfer form immediately after its introduction. ${ }^{8,9}$ In contrast, we believe our study is the first to evaluate the effectiveness of a standardized transfer form many years after its implementation in a large number of nursing homes in a health care system. We demonstrated that, many years after the introduction of this standard transfer form, compliance with its use and completeness of the information on the form is problematic. This study is the first to show that descriptive detail of the presenting complaint that would be helpful to the EP is frequently missing. Our findings suggest that ED care for nursing home patients may not be optimally efficient or safe because of information gaps. Other strategies in addition to a standardized transfer form should be explored to address transfer documentation as this study and others have 
demonstrated that significant information gaps exist even when the transfer form is used.

Our study had a number of strengths. We had a robust case-finding mechanism involving the use of a national database. We captured consecutive transfers from nursing homes and performed a detailed data abstraction describing all clinically important information gaps. We carried out the study at a single hospital only. However, we do not feel this limits the study's generalizability because the city's ambulance system results in transfers from 32 different nursing homes and seniors residences to this hospital. Finally, we had a much larger sample size for transfer form analysis than previous attempts at studying this issue. Future studies should address the clinical impact of these information gaps as our study was only designed to determine the extent of the communication problem.

Our data suggests that the use of a standardized transfer form can reduce the number of information gaps, but not sufficiently. To greatly improve this issue, collaborative efforts between EDs and nursing homes are required. After obtaining the data presented here, we worked with local nursing homes to improve transfer communication and have reason to believe that there has been a qualitative improvement in local practice, which should be encouraging to other communities.

\section{Limitations}

Despite the strengths of our study, there are also some limitations. Through a detailed review of the health records, we found that 133 patients, whose originating address was a nursing home or seniors residence, had no transfer documentation on file at the hospital and so could not be included for analysis. There are 2 possible reasons: either the transfer documentation was lost or it did not exist in the first place. Our final population for this study was 457 transfers after excluding these 133 and thus our data may actually underestimate the magnitude of the problem if the documentation did not exist in the first place for a portion of the 133 cases. If we had data on these cases, our study sample would have been larger, but the information gaps reported on the 457 would still be present. Another limitation of this retrospective review is that it was not possible to capture any verbal communication that may have occurred as part of the transfer. In our experience, it is rare for nursing or medical staff from the nursing homes to phone the ED to discuss a transfer. We rely heavily on the written transfer information at our institution. It is common practice to phone the nursing home after assessing a patient if there is inadequate transfer information; however, this can be time-consuming for the EP and it may be problematic if nursing home staff who had observed the deterioration or were familiar with the patient were no longer on duty. Thus a prospective study would be more effective at capturing and quantifying any oral communications between the institutions and measuring information gaps.

\section{CONCLUSION}

Information gaps occur in almost all instances when seniors are transferred to the ED from a nursing home or seniors residence. Identifying that this problem exists in Canada will help fortify the growing realization that this issue has widespread relevance for health care systems with aging populations. A standardized transfer form results in only a modest improvement in the frequency of information gaps. Based on this work, we make 2 recommendations: 1) there is a need to understand the importance of information gaps on clinical outcomes and processes of care; 2) there is a need to improve the current system of transfer documentation, which could be accomplished through educational interventions, regulatory requirements and greater communication between nursing homes and EDs to discuss methods of optimizing care for patients. Additionally, the form itself could be improved. Our recommendations would be to redesign the transfer form to abbreviate some sections and to give added emphasis to both the history of present illness and the description of baseline cognitive function and verbal communication ability of the patient.

Acknowledgement: We would like to acknowledge My-Linh Tran for her technical support and for maintaining the database.

Competing interests: Dr. Forster is a Career Scientist with the Ontario Ministry of Health and Long-term Care

\section{REFERENCES}

1. Stiell A, Forster AJ, Stiell IG, et al. Prevalence of information gaps in the emergency department and the effect on patient outcomes. CMAJ 2003;169:1023-8.

2. Cook RI, Render M, Woods DD. Gaps in the continuity of care and progress on patient safety. BMJ 2000;320:791-4.

3. Cordell WH, Overhage JM, Waeckerle JF. Strategies for improving information management in emergency medicine to meet clinical, research, and administrative needs. information management work group. Acad Emerg Med 1998;5:162-7. 
4. Smith PC, Araya-Guerra R, Bublitz C, et al. Missing clinical information during primary care visits. JAMA 2005;293:565-71.

5. Gaddis GM. Elder care transfer forms. Acad Emerg Med 2005;12:160-1.

6. Bullard MJ, Unger B, Spence J, et al. Revisions to the CTAS adult guidelines. CJEM 2008;10:136-42.

7. Jones JS, Dwyer PR, White LJ, et al. Patient transfer from nursing home to emergency department: outcomes and policy implications. Acad Emerg Med 1997;4:908-15.

8. Madden C, Garrett J, Busby-Whitehead J. The interface between nursing homes and emergency departments: a community effort to improve transfer information. Acad Emerg Med 1998;5:1123-6.
9. Terrell KM, Brizendine EJ, Bean WF, et al. An extended care facility-to-emergency department transfer form improves communication. Acad Emerg Med 2005;12:114-8.

10. Ontario Hospital Association. Knowledge Centre - Hospital Management Resources (Form \# 122). Toronto (ON): The Association; 2009. Available: www.oha.com/Client /OHA/OHA_LP4W_LND_WebStation.nsf/page/Knowledge +Centre+-+Hospital+Management+Resources (accessed 2009 Jul 28).

Correspondence to: Matthew Cwinn, Department of Emergency Medicine, Rm. M2389-G, The Ottawa Hospital, 501 Smyth Rd., Ottawa ON K1H 8L6; acwin044@uottawa.ca 


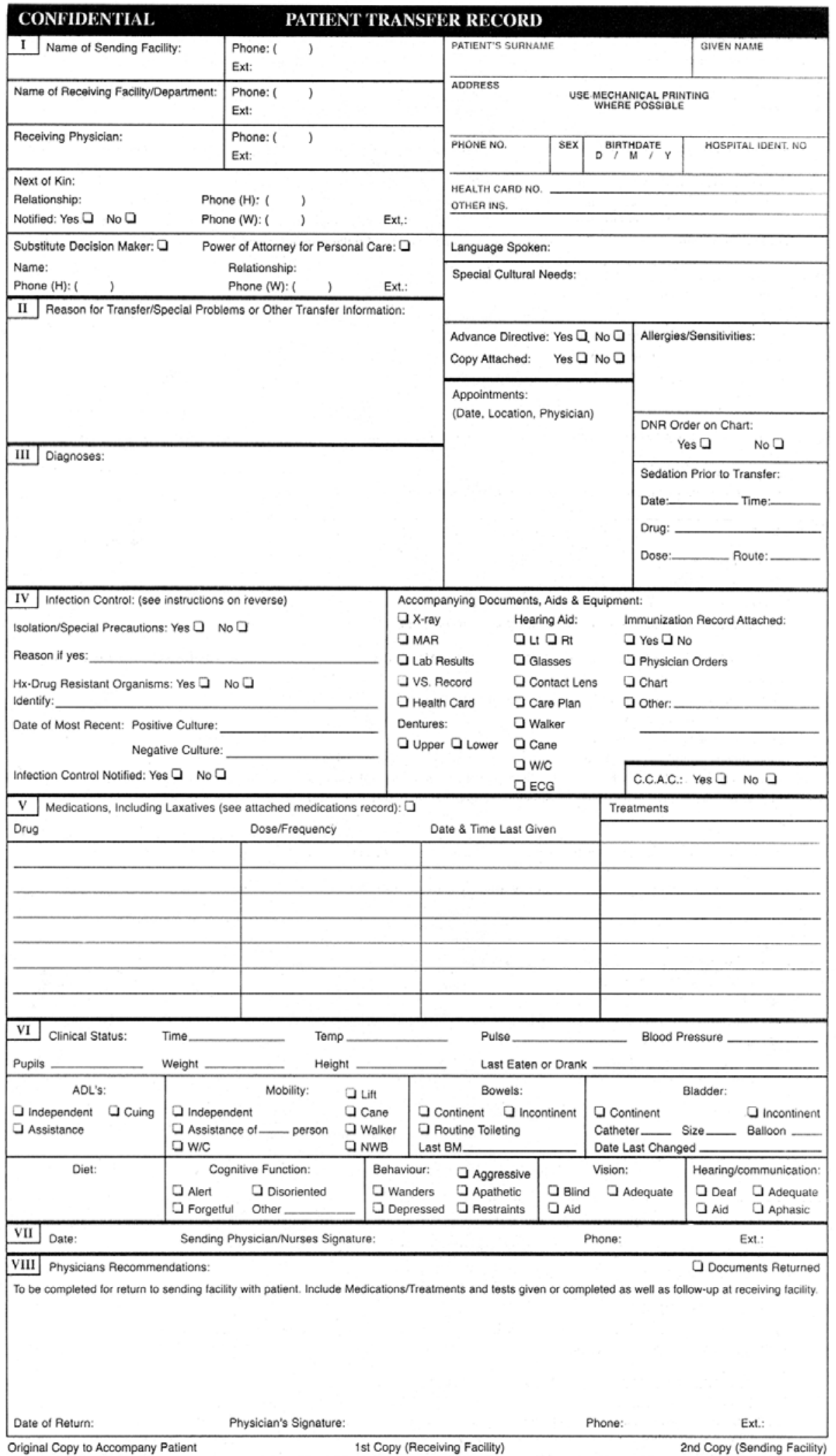

Appendix 1. Patient Transfer Record. ${ }^{10} @$ Ontario Hospital Association. Reproduced with permission. 


\section{CAEP Research Grant Competition \\ Deadline: Friday, December 11, 2009 @ 1200 noon EST \\ Results to PI: Monday, March 15, 2010}

CAEP's Research Committee is proud to bring you the 2010 Research Grant Competition.

Please submit your research grant proposal online via the research page on the CAEP website. Please make note of the dates for deadline for submission and results stated above.

\section{GENERAL INFORMATION}

Consideration will be given to applications submitted by physicians and fellows from diverse settings, including academic, nonacademic, community and rural.

\section{FUNDING INFORMATION}

Maximal support to an individual project will be $\$ 5000$. The grant cannot be considered as supplement to other funding resources. No funding will be provided for meeting registration, travel or equipment purchases.

\section{PREREQUISITE FOR SUBMISSION OF PROPOSALS}

- Principal investigator (PI) and responsible supervisor (for applications of residents and fellows) must be current CAEP members at the time of application

- PI will have less than 8 years of postgraduate (medical school) training

- An accompanying letter from the responsible supervisor must complement the proposal for residents and fellows who are PIs

\section{APPLICATION PROCESS}

Proposals must be no more than 5 pages of single-spaced text, excluding references and appendices. Size 12 font and 1" margins are mandatory. No cover letter is needed. The proposal should be built as one Word file with the following capitalized titles and page numbers:

- Structured Research Abstract (page 1);

- Introduction, Rationale, Research Question, and Methods (limit: 3 pages; pages 2-4);

- Timeline, Impact of the Proposed Study, Future Plans (limit: 1 page; page 5);

- References (as Appendix A, limit to 30 references and 2 pages);

- Research Data Collection Tool (as Appendix B; if more than one, mark B1, B2);

- Detailed Budget and Justification (as Appendix C);

- Curriculum Vitae of the Principal Investigator ONLY (as Appendix D);

- Accompanying Letter from the Responsible Supervisor (as Appendix E; 1 page).

\section{REVIEWERS MAINLY CONSIDER}

- Relevancy to emergency medicine;

- Methodological quality;

- Originality of the topic and methodology;

- Level of training; and

- Ability to complete the proposed study.

\section{SUCCESSFUL INVESTIGATORS WILL PROVIDE A LETTER STATING THAT THEY WILL}

- Provide a final report on the research project up to 15 months after allocation of money;

- Return any unused funds to CAEP up to 15 months after allocation of money; and

- Present the results of the study at the CAEP annual meeting.

For further information contact: Jennifer Lafreniere, CAEP Head Office, 104-1785 Alta Vista Dr., Ottawa ON K1G 3Y6; 613 523-3343 or 800 463-1158 x17; fax 613 523-0190; jlafreniere@caep.ca 